\title{
A randomized trial of ethics education for medical house officers
}

\author{
Daniel P Sulmasy, Gail Geller, David M Levine and Ruth R Faden
}

The fohns Hopkins Medical Institutions, Baltimore, Maryland, USA

\begin{abstract}
Authors' abstract
We report the results of a randomized trial to assess the impact of an innovative ethics curriculum on the knowledge and confidence of 85 medical house officers in a university hospital programme, as well as their responses to a simulated clinical case. Twenty-five per cent of the house officers received a lecture series (Limited Intervention or LI), 25 per cent received lectures and case conferences, with an ethicist in attendance (Extensive Intervention or EI), and 50 per cent served as controls. A post-intervention questionnaire was administered. Knowledge scores did not differ among the groups. Confidence regarding ethical issues was significantly greater in the aggregate intervention group ( 3.9 on a 1 to 5 scale) compared to the control group (3.6). Confidence regarding procedural issues related to ethics was significantly higher for the EI group than for the controls $(4.0 v 2 \cdot 8)$. Responses to a simulated case showed that significantly fewer house officers in the EI group would intubate a patient for whom such therapy would be futile ( $E I=57$ per cent, $L I=87$ per cent, Controls $=82$ per cent). We conclude that ethics education can have an impact on house officers' confidence and their responses to a simulated case, and that the EI was more effective than the LI. Such results have implications regarding the implementation of ethics education during residency.
\end{abstract}

\section{Background}

Medical ethics education during residency training has lagged behind the growth of such programmes for medical students (1). Yet, both the American Board of Pediatrics and the American Board of Internal Medicine call for ethics education during residency and both groups test for competency in ethics in their certifying examinations $(2,3,4)$. Currently, less than half of all internal medicine residency training programmes in the US teach ethics as a formal part of their curriculum (5). One

\section{Key words}

Medical ethics; medical education; internship and residency; curriculum; resuscitation; futility. potential barrier to the broader implementation of ethics training is the fact that little is known about the impact of ethics education for medical house officers. As a result, Pellegrino recently called for the development of research methods and measures to help determine whether or not teaching medical ethics or the medical humanities has a demonstrable effect on the behaviour of physicians (6). Previous studies (7) have shown that physicians who have had ethics training in medical school feel better prepared to address ethical issues in practice than those who do not. We have recently reported that while most medical house officers in our programme report having had ethics education in medical school, their confidence in addressing ethical issues is strongly correlated with their ratings of the quality of that: ethics education (8). A study of paediatricians demonstrated an effect of ethics education during residency on paediatric residents' attitudes towards the resuscitation of certain critically ill children, but concluded that the residency experience itself had a more profound impact on such attitudes than did the ethics course (9). A recent study has documented immediate improvements in the selfassessed knowledge and skills of medical residents regarding advance directives after a two-hour training session using simulated patients (10).

We are unaware of any controlled trials of ethics education in internal medicine residency training programmes. We have therefore undertaken a randomized controlled trial of ethics education for medical house officers to determine the impact of such education on house officers' knowledge of medical ethics, confidence in addressing ethical issues, and responses to a simulated case involving resuscitation.

\section{Subjects and methods}

The Osler Medical Service of the Johns Hopkins Hospital, Baltimore, Maryland, is a universitybased, categorical, internal medicine residency training programme. The house officers at Johns Hopkins are assigned as interns to one of four 'firms' in a consecutive, alternating, alphabetical fashion after stratification for gender and graduation from the 
Johns Hopkins Medical School. Each house officer is a member of the same 'firm' for all three years of training. House officers provide both inpatient and ambulatory care with that firm for the entire residency, and only rotate with members of other firms when assigned to specific services or specialized units. Each firm consists of approximately seven interns, 12 residents and a junior attending physician known as the assistant chief of service, who is responsible for the firm.

During the $1988-89$ academic year, one firm was randomized to receive a Limited ethics education Intervention (LI). This consisted of a series of six lectures from October, 1988 through April, 1989, addressing ethical vocabulary, principles, landmark court decisions, and local law. The curriculum for these lectures has been described previously (8). A second firm received an Extensive ethics education Intervention (EI). This consisted of the six ethics lectures plus a series of six case conferences in which house officers chose cases which they viewed as raising issues of ethical concern, such as termination of treatment decisions or questions regarding confidentiality. The EI firm was also assigned an assistant chief of service with formal training in ethics (Dr Sulmasy), who was responsible for patient care and much of the teaching on the firm. The other two firms (Control 1-C1) and (Control $2-\mathrm{C} 2$ ) received no specific training in ethics and served as an aggregate control group (Total Control - TC). There had been no previous formal ethics training for medical house officers at the institution prior to this intervention. The assistant chiefs of service for the LI firm and the control firms had no formal training or specific academic interest in ethics.

Approval for the study was obtained from the Joint Committee on Clinical Investigation of the Johns Hopkins University School of Medicine.

At the end of the 1988-89 academic year, one month after the last session was held for the intervention groups, the medical house officers were surveyed using a confidential, self-administered questionnaire to ascertain their levels of knowledge and confidence regarding ethical issues, their responses to a simulated case which raised ethical concerns, and basic demographic information. The knowledge and confidence scales of this questionnaire have been described in detail elsewhere (8). The questionnaire is available in its entirety upon request. Informed consent was obtained from each house officer by telephone prior to sending a questionnaire. Three of the 88 medical house officers declined participation. Sixty-four of the 85 eligible house officers returned their questionnaires for a response rate of 75 per cent. Women were less likely to return the questionnaire than men ( 56 per cent v 85 per cent, $P<0.05)$. Responders did not differ from non-responders with respect to postgraduate year.

\section{VARIABLES MEASURED}

\section{1: Knowledge and confidence}

The knowledge test consisted of 15 multiple-choice questions directly related to the lecture material. For example, house officers were asked whether Maryland had a living will statute and about the definition of utilitarianism. The test had face validity when reviewed by a panel of experts, and was found reliable ( $\mathrm{r}$ for redundant question $=0.8, \mathrm{P}<0.001$ ). The confidence scale was modelled on the work of Bandura et al (11), and assessed, on a five-point spread, house officers' confidence in 1) recognising ethical problems; 2) making decisions about ethical problems; 3) explaining these decisions; 4) obtaining genuine informed consent; 5) knowing how to proceed when the patient is incompetent; 6 ) addressing ethical issues in the care of the terminally ill. Scores for the scale were obtained by summing responses to the six items, and dividing by six, for a range of one (low confidence) to five (high confidence). Cronbach's alpha (a method of measuring internal consistency) for the six-item confidence scale was 0.76 for the survey sample. A subscale consisting only of the last two confidence items (caring for the incompetent and the terminally ill) became evident in factor analysis. Conceptually, these two items seemed to reflect confidence in more practical and procedural matters related to ethics, while the first four items related better to matters which were more abstract and related to communication skills. Scores for this subscale were obtained by summing the responses to these two items and dividing by two. Cronbach's alpha for this subscale was 0.74 for the survey sample.

\section{2: Simulated case}

The final section of the questionnaire described in detail the case of a 48-year-old man with his second documented recurrence of squamous cell carcinoma of the oesophagus, status post both surgery and maximal radiation therapy, who developed a Boerhaave syndrome and presented with fever and respiratory distress $\left(\mathrm{pO}_{2}\right.$ of $55 \mathrm{~mm} \mathrm{Hg}$ on a 100 per cent facemask) in the emergency room. The case was designed to convey a situation of therapeutic futility. Respondents were asked to imagine that they were the doctor caring for the patient and to select, from among the following choices, the course of action they would elect to take: 1) intubate the patient; 2) ask the patient whether he wants 'heroic' measures; 3) neither intubate nor elicit patient preferences, but admit to the floor with $\mathrm{O}_{2}$, antipyretics, and morphine.

\section{Statistical analysis}

Dichotomous outcomes were compared using the chi-square or Fisher's exact test as appropriate. Knowledge scores were compared using the Student's t-test. Confidence scales were compared using the Wilcoxon rank-sum test. 


\section{RESULTS}

Firms did not differ significantly in age, gender, race, religion, or postgraduate year (see Table 1). However, the perceived quality of medical school ethics education did differ significantly among the firms $(p<0.05)$. In one of the two control firms (C1), only 15 per cent rated their previous training in ethics as excellent. In the other control firm (C2), 60 per cent of the house officers rated their medical school ethics training as excellent. Taken together as a single control group, however, 35 per cent of the total control group (TC) rated their previous ethics education as excellent, which did not differ significantly from the 40 per cent for the limited intervention (LI) group or the 31 per cent for the extensive intervention (EI) group.

The educational sessions were well received. The lectures were rated extremely stimulating by 11 per cent of the house officers, and stimulating by 74 per cent. The conferences were rated as extremely stimulating by 33 per cent, and stimulating by 61 per cent.

\section{Knowledge}

The questionnaire was administered one month after the last session took place for the intervention groups. The percentage correct on the knowledge test was uniformly low for all groups $(\mathrm{C} 1=53$ per cent, $\mathrm{C} 2=58$ per cent, $\mathrm{LI}=56$ per cent, $\mathrm{EI}=57$ per cent). There were no significant differences among groups for any particular question nor for summary measures of either the practical questions (for example, those dealing with informed consent, local law, Jehovah's Witnesses) or the theoretical questions (for example, those dealing with specific philosophical principles or vocabulary, such as the definitions of deontology and utilitarianism). Details of the aggregate house officer knowledge scores have been presented elsewhere (8).

\section{Confidence in addressing ethical issues}

Confidence was also measured by questionnaire one month after the last session took place for the intervention groups. The overall confidence scores for the control groups were $\mathrm{C} 1=3 \cdot 4$ and $\mathrm{C} 2=3 \cdot 8$. The confidence scores were 3.9 for the LI group, and 3.8 for the EI group. The confidence score for the aggregate intervention group (LI+EI) was 3.9, which was significantly higher than the total controls $(3 \cdot 6, P<0 \cdot 05)$. Since the groups were not equivalent in previous training, and since our earlier work has shown that the perceived quality of medical school ethics training is a strong predictor of confidence in addressing ethical problems, we stratified by previous training in order to assess the effect of the ethics education intervention independent of the previous training. These results are shown in Table 2 . It is evident that the intervention during residency was associated with a significantly higher confidence for the EI group compared to controls $(3.7 \times 3.3, P<0.05)$, but only for those who reported a poorer preparation in medical school. Among those reporting that their background was 'excellent', confidence was uniformly high for all groups.

In addition, we looked at the subscale of confidence related only to practical and procedural concerns (confidence in knowing how to proceed when a patient is incompetent and in addressing ethical issues in the care of the terminally ill). There were no statistically significant differences between the two control groups in procedural confidence. The aggregate procedural confidence score for the control groups (TC) was $2 \cdot 8$. The score for the LI group was $3 \cdot 5$, and the score for the EI group was $4 \cdot 0$. This latter score was significantly higher than the controls $(\mathbf{P}<0.05)$. These results are shown in Figure 1.

\section{Simulated case}

There were no differences between the two control firms or between the total control group and the LI group. However, house officers in the EI group were significantly less likely either to intubate immediately or to elicit patient preferences regarding intubation when compared to all other groups $(P<0 \cdot 05)$. Fortythree per cent of the EI group elected instead to admit the patient to the floor with $\mathrm{O}_{2}$, antipyretics, and morphine (Table 3).

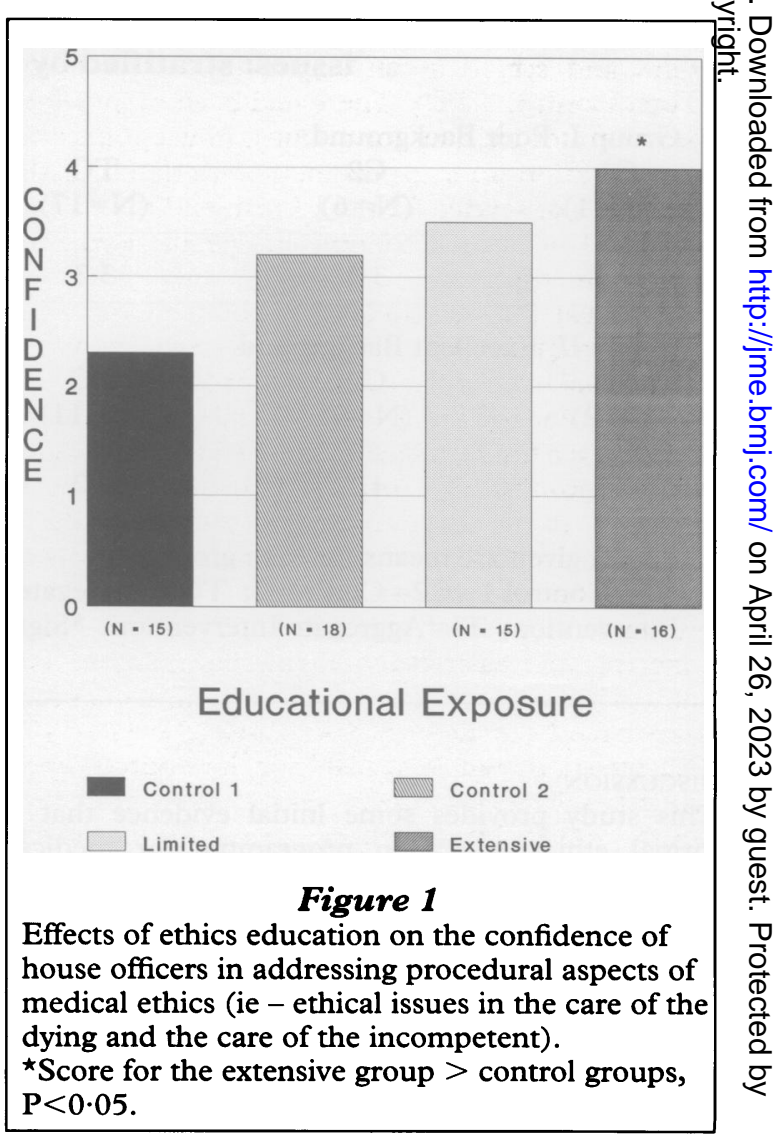


Table 1

House officer characteristics by firm

\begin{tabular}{lcccc} 
Characteristic & $\begin{array}{c}\text { Control } \\
\text { Firm 1 }\end{array}$ & $\begin{array}{c}\text { Control } \\
\text { Firm 2 }\end{array}$ & $\begin{array}{c}\text { Limited } \\
\text { Intervention }\end{array}$ & $\begin{array}{c}\text { Extensive } \\
\text { Intervention }\end{array}$ \\
\hline Number & 15 & 18 & 15 & 16 \\
Age (mean years) & $29 \cdot 0$ & $28 \cdot 6$ & $28 \cdot 7$ & $29 \cdot 3$ \\
Mean Postgraduate Year & $2 \cdot 1$ & $1 \cdot 8$ & $1 \cdot 9$ & $2 \cdot 1$ \\
Percent Women & 7 & 17 & $27^{\star}$ & 13 \\
Religion (\%) & & 33 & 33 & 25 \\
$\quad$ Protestant & 33 & 11 & 27 & 19 \\
$\quad$ Jewish & 13 & 39 & 13 & 38 \\
$\quad$ Catholic & 13 & 6 & 27 & 6 \\
$\quad$ Other & 7 & 11 & 27 & 13 \\
$\quad$ None & 33 & & & 29 \\
Percent Excellent & & $60 \dagger$ & 40 & \\
$\quad$ Med School & 15 & & & \\
\hline
\end{tabular}

${ }^{\star} P=0 \cdot 14$ compared with Control Firm 1 . †significantly greater than Control Firm $1, P<0 \cdot 05$. No other significant differences were noted.

Table 2

Effect of ethics education on house officers' confidence in addressing ethical issues: stratified by medical school training

Group I: Poor Background

\begin{tabular}{|c|c|c|c|c|c|}
\hline $\begin{array}{c}\mathrm{Ci} \\
(\mathrm{N}=11)\end{array}$ & $\begin{array}{c}\mathrm{C} 2 \\
(\mathrm{~N}=6)\end{array}$ & $\begin{array}{c}\mathrm{TC} \\
(\mathrm{N}=17)\end{array}$ & $\begin{array}{c}\mathrm{LI} \\
(\mathrm{N}=9)\end{array}$ & $\begin{array}{c}\mathrm{EI} \\
(\mathrm{N}=11)\end{array}$ & $\begin{array}{c}\mathrm{TI} \\
(\mathrm{N}=20)\end{array}$ \\
\hline $3 \cdot 3$ & $3 \cdot 4$ & $3 \cdot 3$ & $3 \cdot 6$ & $3 \cdot 7^{\star}$ & $3 \cdot 7^{\star}$ \\
\hline \multicolumn{6}{|c|}{ Group II: Excellent Background } \\
\hline $\begin{array}{c}\mathrm{C} 1 \\
(\mathrm{~N}=2)\end{array}$ & $\begin{array}{c}\mathrm{C} 2 \\
(\mathrm{~N}=9)\end{array}$ & $\begin{array}{c}\mathrm{TC} \\
(\mathrm{N}=11)\end{array}$ & $\begin{array}{c}\mathrm{LI} \\
(\mathrm{N}=6)\end{array}$ & $\begin{array}{c}\mathrm{EI} \\
(\mathrm{N}=5)\end{array}$ & $\begin{array}{c}\mathrm{TI} \\
(\mathrm{N}=11)\end{array}$ \\
\hline $4 \cdot 3$ & $4 \cdot 1$ & $4 \cdot 2$ & $4 \cdot 4$ & $4 \cdot 0$ & $4 \cdot 2$ \\
\hline
\end{tabular}

Scores given are means for each group.

$\mathrm{C} 1=$ Control 1; $\mathrm{C} 2=$ Control 2; $\mathrm{TC}=$ Aggregate Control; $\mathrm{LI}=$ Limited Intervention; $\mathrm{EI}=$ Extensive Intervention; $\mathrm{TI}=$ Aggregate Intervention. ${ }^{\star}$ Significantly greater than $\mathrm{TC}, \mathrm{P}<0.05$

\section{DISCUSSION}

This study provides some initial evidence that a formal ethics education programme for medical house officers can improve the confidence of house officers in addressing ethical problems and can alter their approach to a simulated case. It can be argued that it is not necessary to demonstrate an effect of ethics education for medical students or residents in order to justify teaching ethics, any more than it is necessary to demonstrate an effect of biochemistry education in order to justify teaching biochemistry
(6). Nonetheless, the evaluation of the impact of new and evolving ethics curricula can help to guide future curricular development. And the demonstration of a positive effect of ethics education supports arguments in favour of more widely implementing formal ethics education in residency training.

The findings with respect to confidence suggest that house officers who report having received an 'inadequate' or 'barely adequate' ethics education in medical school are likely to experience an increase in their confidence in addressing ethical problems if 


\section{Table 3 \\ Effects of ethics education on decision making in a simulated case}

Question: How would you approach the case of an imminently $(<24 \mathrm{hrs})$ dying cancer patient with no remaining therapeutic options for cancer treatment, but in respiratory distress?

$\begin{array}{ccc}\begin{array}{c}\text { Control } \\ (\mathrm{N}=33)\end{array} & \begin{array}{c}\mathrm{LI} \\ \mathrm{N}=15)\end{array} & \begin{array}{c}\mathrm{EI} \\ (\mathrm{N}=16)\end{array} \\ 2(6 \%) & 0(0 \%) & 0(0 \%) \\ 25(76 \%) & 13(87 \%) & 9(57 \%)\end{array}$

re: intubation

$25(76 \%)$

$13(87 \%)$

Inform of gravity,

give comfort measures,

no intubation, no

preference elicitation

$6(18 \%)$

$2(13 \%)$

$7(43 \%)$

$\mathrm{LI}=$ Limited Intervention; $\mathrm{EI}=$ Extensive Intervention. EI less likely to intubate or elicit preferences for intubation as compared to controls $(P<0.05)$ and $\mathrm{LI}(\mathrm{P}=0.06)$.

they have a formal ethics education programme during residency. Interestingly, those who report an 'excellent' background in medical school seem already to be confident about their ability to address ethical problems in residency, and this high confidence persists regardless of the ethics education they receive as residents. Unfortunately, only a minority (37 per cent) of house officers reported that their background was 'excellent', and 0 per cent reported that their previous training was 'so good that no further training is necessary'. This suggests a need to continue ethics education beyond the medical school years into residency. In particular, house officers' confidence regarding procedural skills related to ethics was positively affected by the intervention. It may be the case that these aspects of medical ethics are best taught during residency.

Since confidence has been shown to predict behaviour $(11,12)$, an improvement in confidence is considered a favourable result of the intervention. Unfortunately, we cannot test the confidencebehaviour hypothesis in relation to individual physicians in the present study. Because of an ethical obligation to preserve the anonymity of the house officers' responses, we do not have the data with which to associate the confidence scores of individual house officers with their individual practice patterns. However, data from a corollary study we are conducting indicate that, in the aggregate, house officers who receive extensive ethics education not only have higher confidence, but also perform in a superior fashion when addressing ethical issues in the care of patients with orders not to resuscitate (13). We are continuing to investigate the effects of ethics education on the actual practices of medical house officers.
The intervention also had a significant effect on the house officers' responses to the simulated case? There is a growing consensus in the medical ethics literature that biomedically futile interventions (which can neither cure nor sustain life) need not be offered to patients, and that it is not necessary that patients grant permission to withhold such futile therapy $(14,15,16,17)$. This topic arose in the context of several of the case discussions held with the EI group, and thus it is not surprising that this group was significantly more likely to choose neither to intubate nor to elicit the preferences of a patient for whom intubation could not possibly offer more than hours to days of additional life. While this is only a simulated case, it does suggest that the house officers in the EI group would have a different initial approach to such a patient in their practice. Berseth and Durand (9) found that the experience of residency training itself had an important effect upon the attitudes of paediatric house officers regarding a simulated case involving the ethics of resuscitation. They used non-paediatric house officers as their controls with a before-after testing protocol. Our design does not allow us to assess whether the residency experience had a comparable effect on the house officers in our study. Nonetheless, the randomized design of our study supports the inference that the changes seen were the result of our intervention, since the residency experience is otherwise comparable for all the internal medicine firms at our institution.

The data indicate that the intervention had more impact upon house officers' confidence and responses to a simulated case than upon knowledge. Knowledge scores ranged from 53 per cent to 58 per 
cent correct, and were not significantly affected by the intervention. Many of the knowledge items related to practical concerns (such as whether one could, in an emergency, legally and without a court order transfuse a minor whose parents refused to consent based on their beliefs as Jehovah's Witnesses). Such information ought to be part of the fund of knowledge of all house officers (18).

The increase in confidence without a comparable increase in knowledge may seem alarming. However, it may be the case that young physicians often learn correct clinical practices before fully understanding the underlying theory. Similar to our findings, others have reported that an education programme in critical care increased confidence regarding invasive procedures without an increase in knowledge (19). Nonetheless, physicians who understand what they are doing are likely to be better practitioners, especially when they encounter unusual clinical circumstances. The lack of impact on knowledge therefore suggests a need to modify and enhance the intervention to improve the house officers' knowledge base in medical ethics.

The results also indicate that the Extensive Intervention (lectures + case conferences + ethicist in attendance) was more successful than the Limited Intervention (lectures only) in influencing behavioural attitudes. This is not a surprising result. It does, however, raise important questions regarding the relative effects of the various components of the intervention, which this study was not designed to address. In particular, the role of the ethicist in attendance in this multiple-strategy intervention is important to consider further. Was the role-modelling provided by the physician-ethicist the critical factor? If so, one might draw the impracticable conclusion that having an ethicist in attendance would be necessary on every ward in every training programme in order to improve patient care demonstrably in these areas. We hypothesize, however, that sufficient role-modelling can be provided by having ethicists in attendance who are well respected but few in number, providing ethics education to larger groups of house officers. We are currently testing this hypothesis. If this hypothesis proves true, it would underscore a strength and ultimate objective of the intervention: this educational programme can be readily incorporated into existing training programmes. The lectures and case discussions of this intervention were integrated into the routine of a categorical internal medicine training programme in a practical fashion.

The study is limited by the fact that these results are from a single institution, but a controlled trial of this sort would have been inordinately difficult to conduct as a multi-centre study. The small number of house officers is a further limitation, but this does not so much limit our ability to interpret the positive results we report as limit our ability to detect small differences, since our statistical power $(\beta)$ to detect a
15 per cent difference in knowledge scores between the EI group and the controls was only 0.42 . In addition, we have post-testing results only, and cannot compare to a baseline. It is also clear that since the 'firm' system does not completely isolate house officers (who intermingle during certain rotations as well as socially) the strength of the influence of the intervention may have been diminished by a 'contamination' effect. Nonetheless, the results do suggest that ethics education for medical house officers can have a positive impact on both house officers' confidence in addressing ethical problems and their approaches to a simulated case. Based on these results, ethics education is now part of the formal residency curriculum of the Osler Medical Service of the Johns Hopkins Hospital. We are presently studying the long-term effects of this ethics curriculum, particularly regarding effects on actual patient-care practices, as well as developing a broader educational programme in ethics at our institution.

\section{Acknowledgements}

We are grateful to the Osler medical housestaff for their participation in this study and for their dedicated patient cate, to John D Stobo, MD, for the support he has given to ethics education in his training programme, to Alex Seidler, $\mathrm{PhD}$, for statistical advice, and to Lisa Lehmann for technical assistance. Support for this work was provided by the Charles E Culpeper Foundation and a grant from the National Institutes of Health (NHLBI-T32 HL07180). Computations were performed on the CLINFO system (NIH grant RR00035).

Daniel P Sulmasy, OFM, MD, is now Assistant Professor, Division of General Internal Medicine, and Research Scholar, Center for Clinical Bioethics, at the Georgetown University Medical Center. At the Fohns Hopkins Medical Institutions, Gail Geller, ScD, is Assistant Professor, Department of Pediatrics, David M Levine, MD, MPH, ScD, is Professor of Medicine and Director of the Division of General Internal Medicine, and Ruth R Faden, PhD, MPH, is Professor of Health Policy and Director of the Center for Law, Ethics, and Health.

\section{References}

(1) Miles S H, Lane L W, Bickel J, Walker R M, Cassel C K. Medical ethics education: coming of age. Academic medicine. 1989; 64: 705-714.

(2) Medical Ethics Subcommittee of the American Board of Pediatrics. Teaching and evaluation of interpersonal skills and ethical decision making in pediatrics. Pediatrics 1987; 79: 829-833.

(3) Subcommittee on Evaluation of Humanistic Qualities in the Internist: American Board of Internal Medicine. Evaluation of humanistic qualities in the internist. Annals of internal medicine 1983; 99: 720-724. 
(4) Langdon L, Jonsen A R. The experience of the American Board of Internal Medicine. Hastings Center report 1983; 13: 26-27.

(5) Merkel W T, Margolis R B, Smith R C. Teaching humanistic and psychosocial aspects of care: current practices and attitudes. Fournal of general internal medicine 1990; 5: 34-41.

(6) Pellegrino E D. Teaching medical ethics: some persistent questions and some responses. Academic medicine 1989; 64: 701-703.

(7) Pellegrino E D, Hart R J, Henderson S R, Loeb S E, Edwards G. Relevance and utility of courses in medical ethics. Fournal of the American Medical Association 1985; 253: 49-53.

(8) Sulmasy D P, Geller G, Levine D M, Faden R. Medical house officers' knowledge, attitudes, and confidence regarding medical ethics. Archives of internal medicine 1990; 150: 2509-2513.

(9) Berseth C L, Durand R. Evaluating the effect of a human values seminar series on ethical attitudes toward resuscitation among pediatric residents. Mayo Clinic proceedings 1990; 65: 337-343.

(10) Gordon G H, Tolle S W. Discussing life-sustaining treatment: a teaching program for residents. Archives of internal medicine $1991 ; 151$ : 567-570.

(11) Bandura A, Adams N E, Beyer J. Cognitive processes mediating behavioural change. Fournal of personality and social psychology 1977; 35: 125-139.
(12) Geller G, Levine D M, Mamon J A, Moore R D, Stokes E J. Knowledge, attitudes, and reported practices of medical students and house officers regarding the diagnosis and treatment of alcoholism. Fournal of the American Medical Association 1989; 261: 3115-3120.

(13) Sulmasy D P, Geller G, Levine D M, Faden R. The quality of mercy: caring for patients with 'do not resuscitate' orders. Fournal of the American Medical Association 1992; 267: 682-686.

(14) Schneiderman L J, Jecker N S, Jonsen A R. Medical futility: its meaning and ethical implications. Annals of internal medicine 1990; 112: 949-954.

(15) Tomlinson T, Brody $H$. Futility and the ethics of resuscitation. Fournal of the American Medical Association 1990; 264: 1276-1280.

(16) Youngner S J. Futility in context. Fournal of the American Medical Association 1990; 264: 1295-1296.

(17) Faber-Langendoen K. Resuscitation of patients with metastatic cancer: is transient benefit still beneficial? Archives of internal medicine 1991; 151: 235-239.

(18) Culver C M, Clouser K D, Gert B et al. Basic curricular goals in medical ethics. New England journal of medicine 1985; 312: 253-256.

(19) Dunn P M, Kaynard J. Unique educational program in critical care medicine for the general internist. fournal of general internal medicine 1993; 8: 126-129. 